\title{
New observations of late summer bio-physical sea-ice and snow conditions in the northwestern Weddell Sea
}

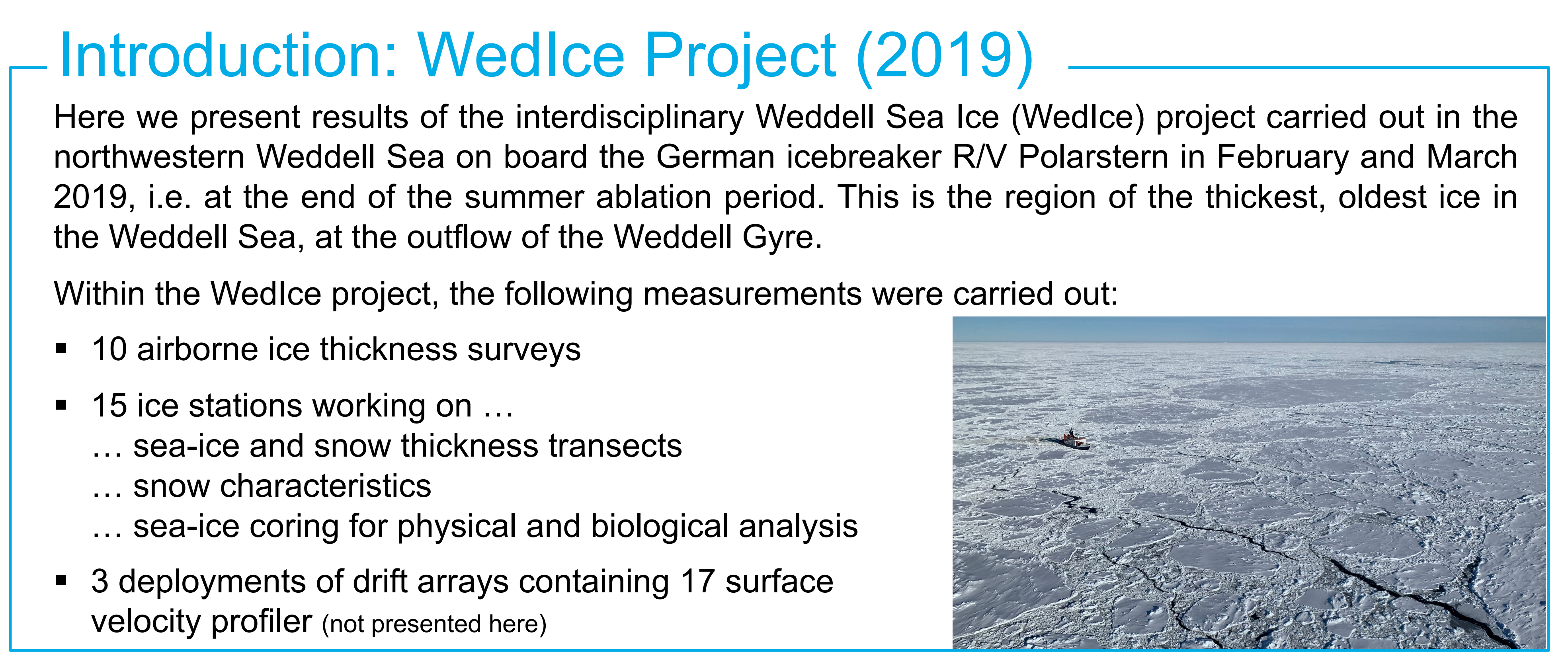

\section{Sea-ice biology}
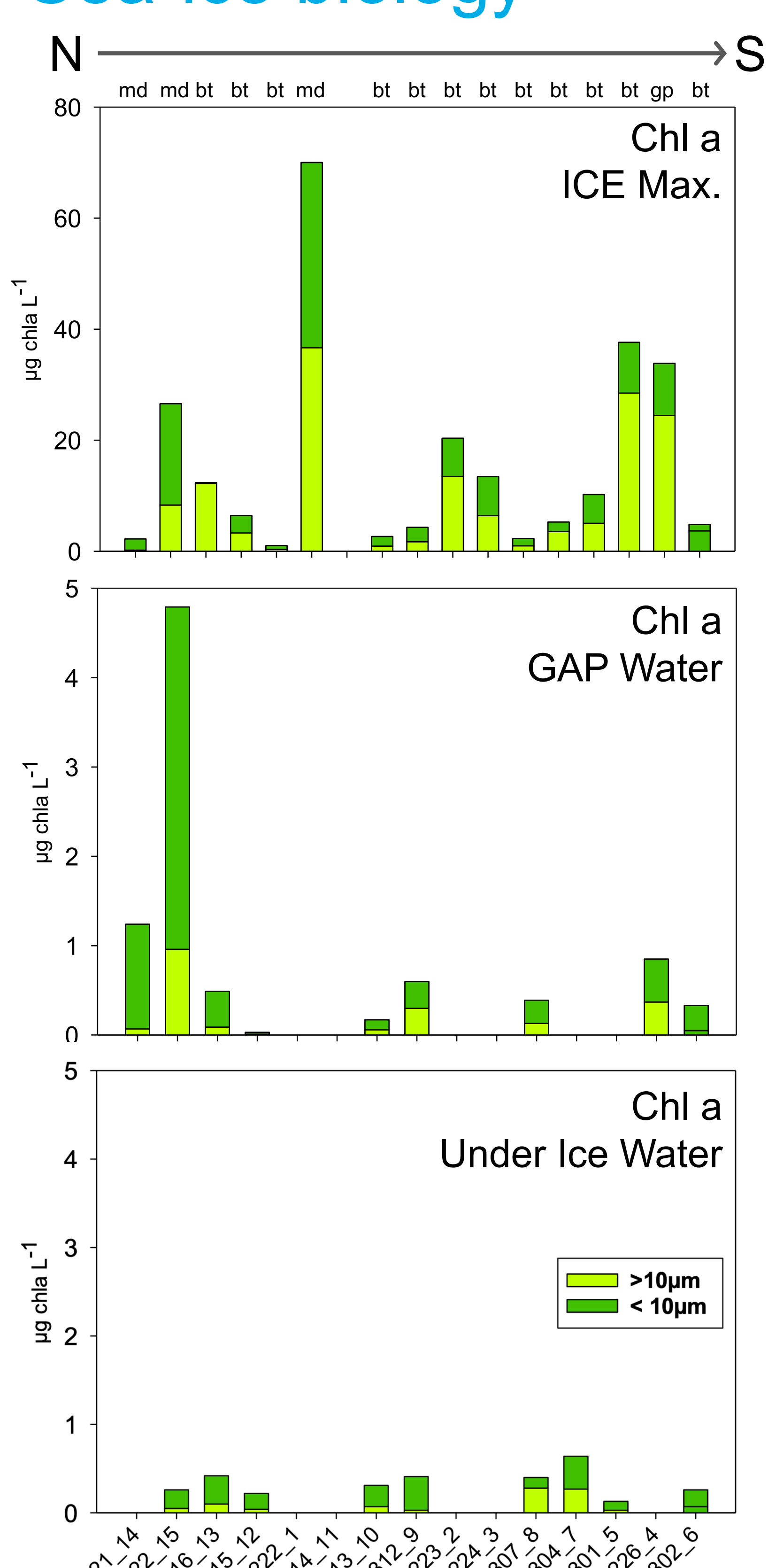

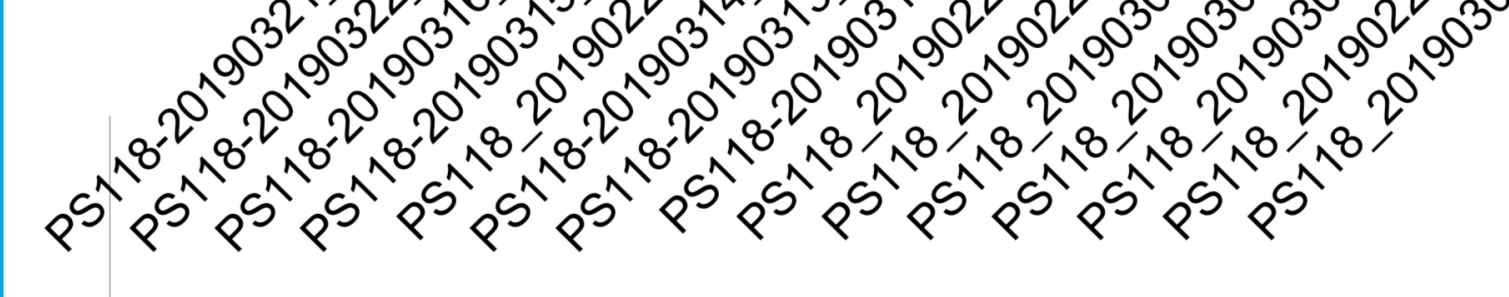

Integrated Ice Chl a Ill, Il , lininlil
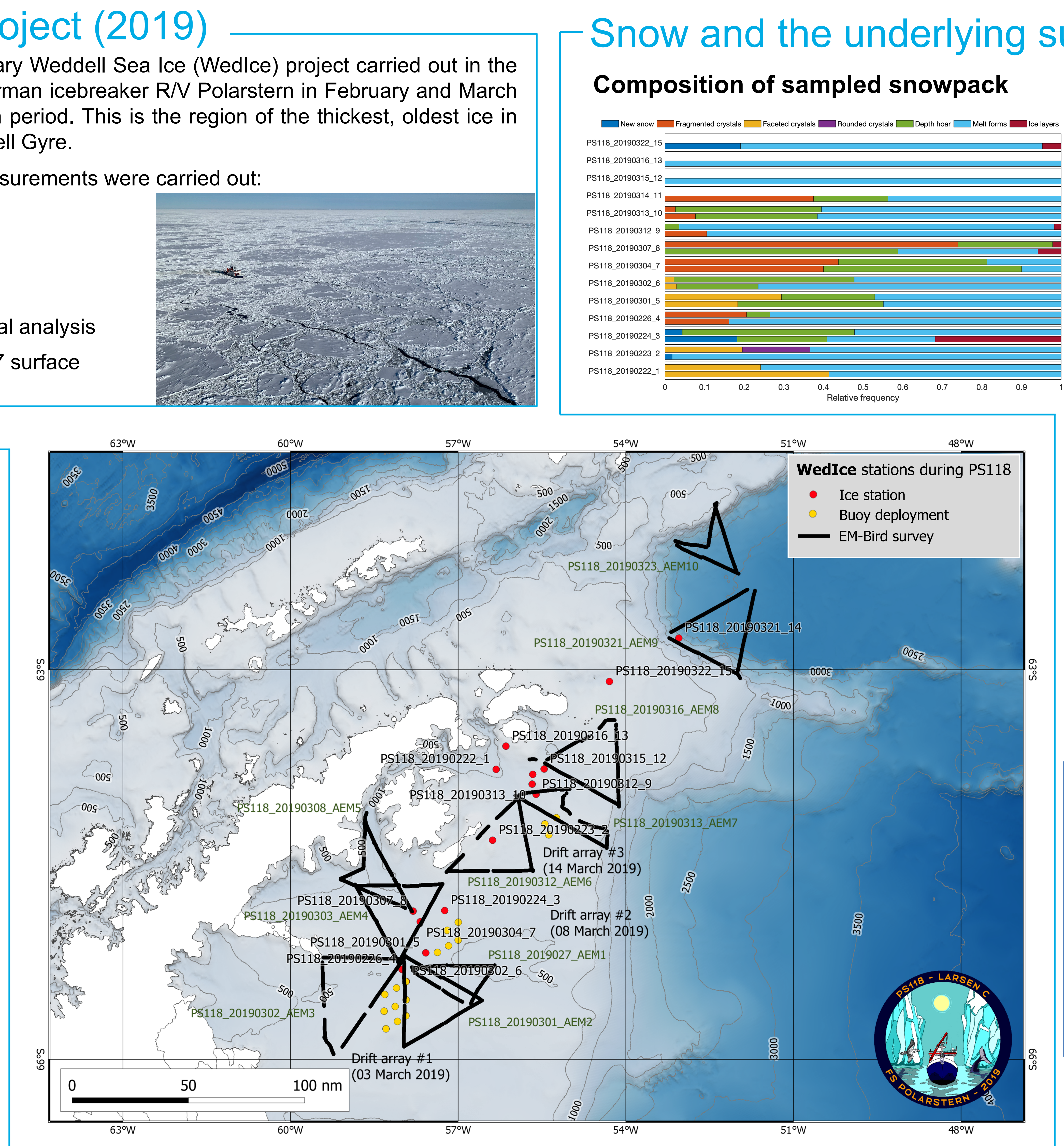
- High concentrations of ice algae biomass
dominated by large species with maxima
in various core sections

(gp: gap, bt: bottom, md: middle)

- Latitudinal gradient in flagellate dominated gap water communities

- Small algae also dominate the low under ice water biomass

\section{Key points}

- Sea ice conditions in the northwestern Weddell Sea are still severe and have not changed significantly since the last observations carried out in 2004/2006

Observed snow depth was comparably low as a consequence of summer's thaw and therefore its significant transition into superimposed ice

The presence of relatively thin, icy snow has strong implications for the sea-ice mass balance, for freshwater oceanography, and for the application of remote sensing methods

Standing stocks of integrated sea ice algae biomass are among the highest observed in Antarctica with a slight "seasonal" trend

Higher trophic levels in the Western Weddell Seas can be related to concentrated food source from the ice

\section{- Sea-ice thickness in the western Weddell Sea}

- The study region was characterized by the presence of at least three different ice regimes: Heavily deformed ice near the coast and A68

A band of younger, thinner, less deformed ice originating from the Ronne Ice Shelf east of (I)

Older, strongly deformed, thick ice originating from the southeastern Weddell Sea in the very east

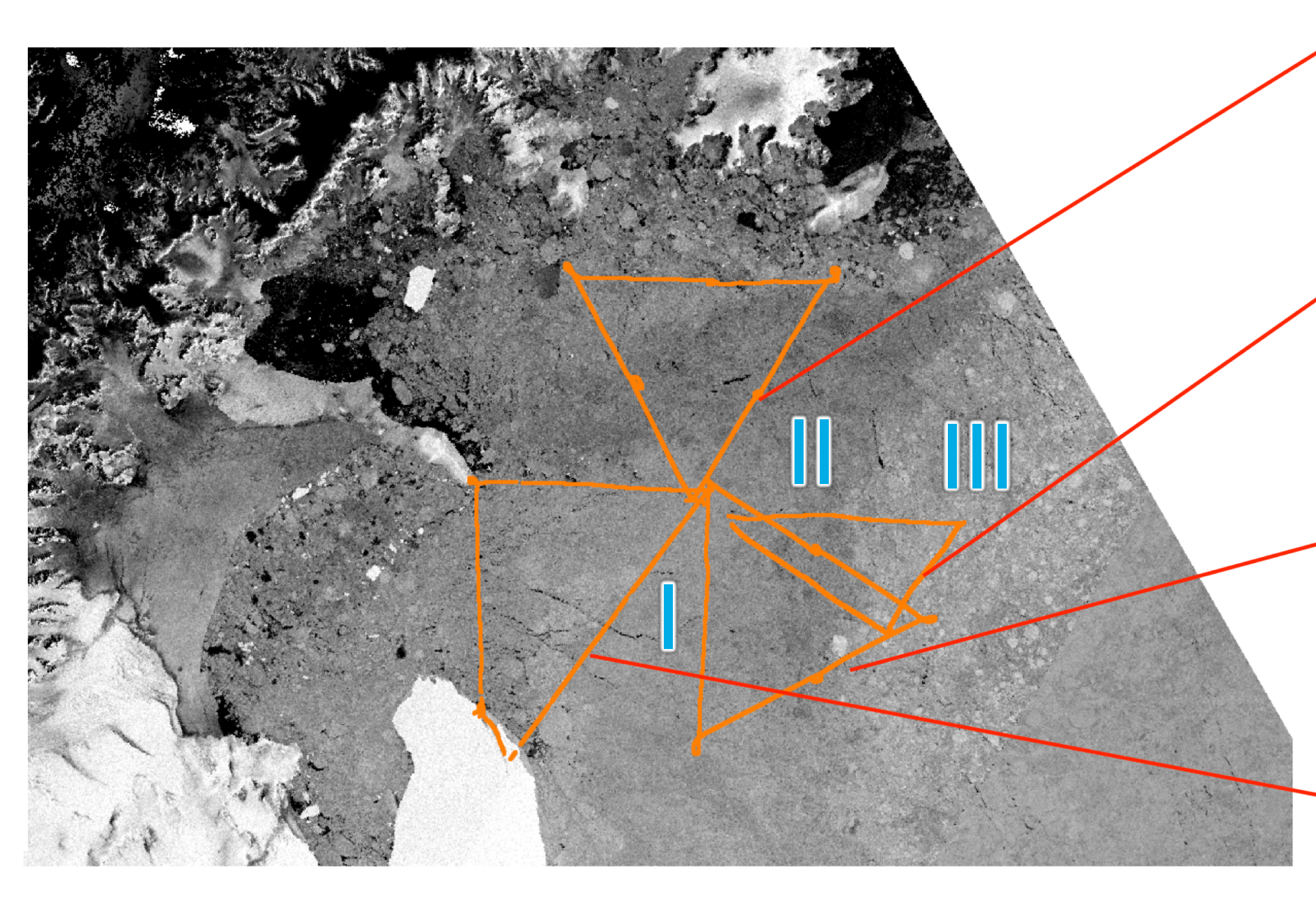

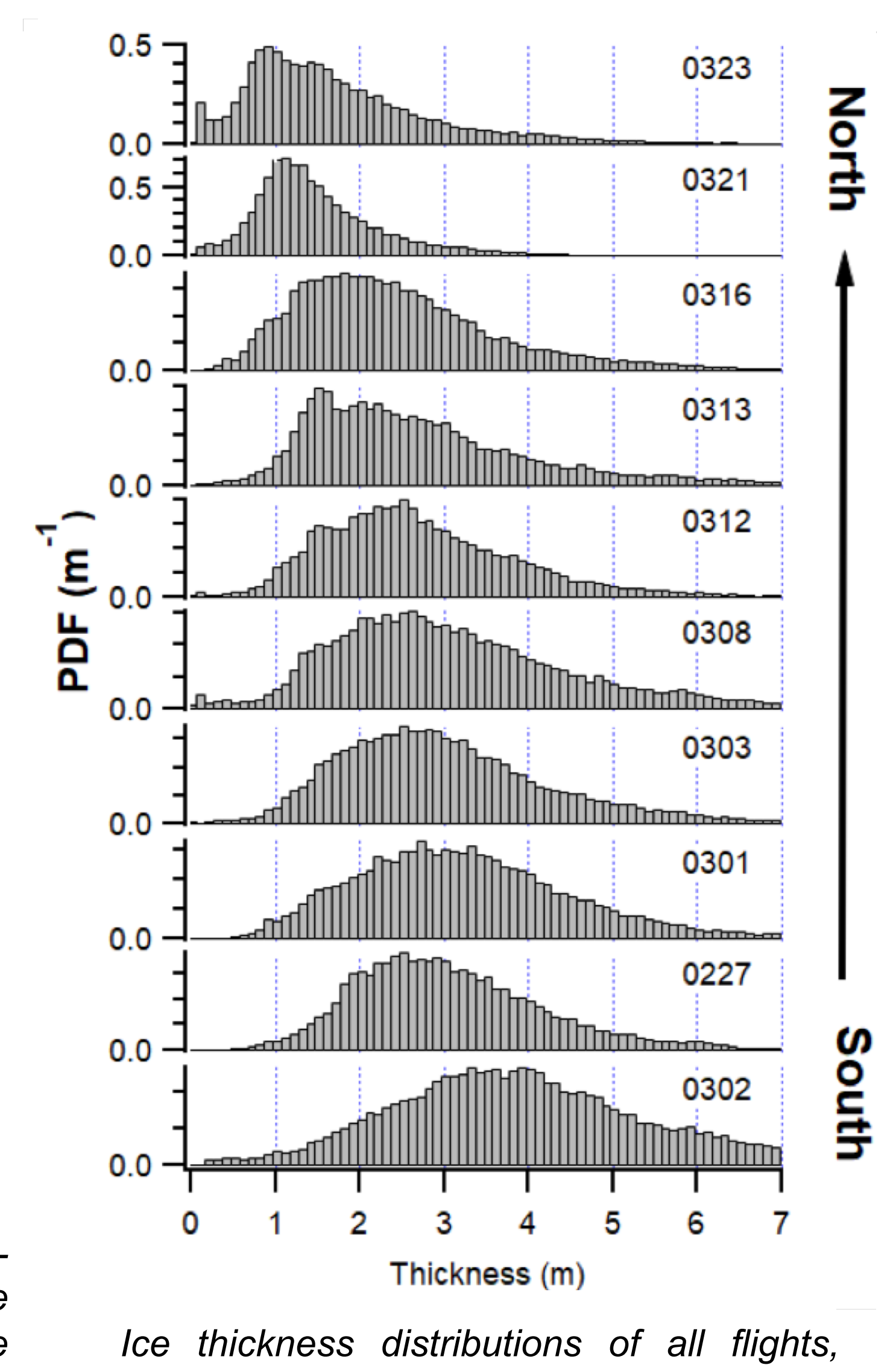

Ice thickness distributions of all flights,
from the south (bottom) to the north (top).
Ground-based snow and sea-ice thickness

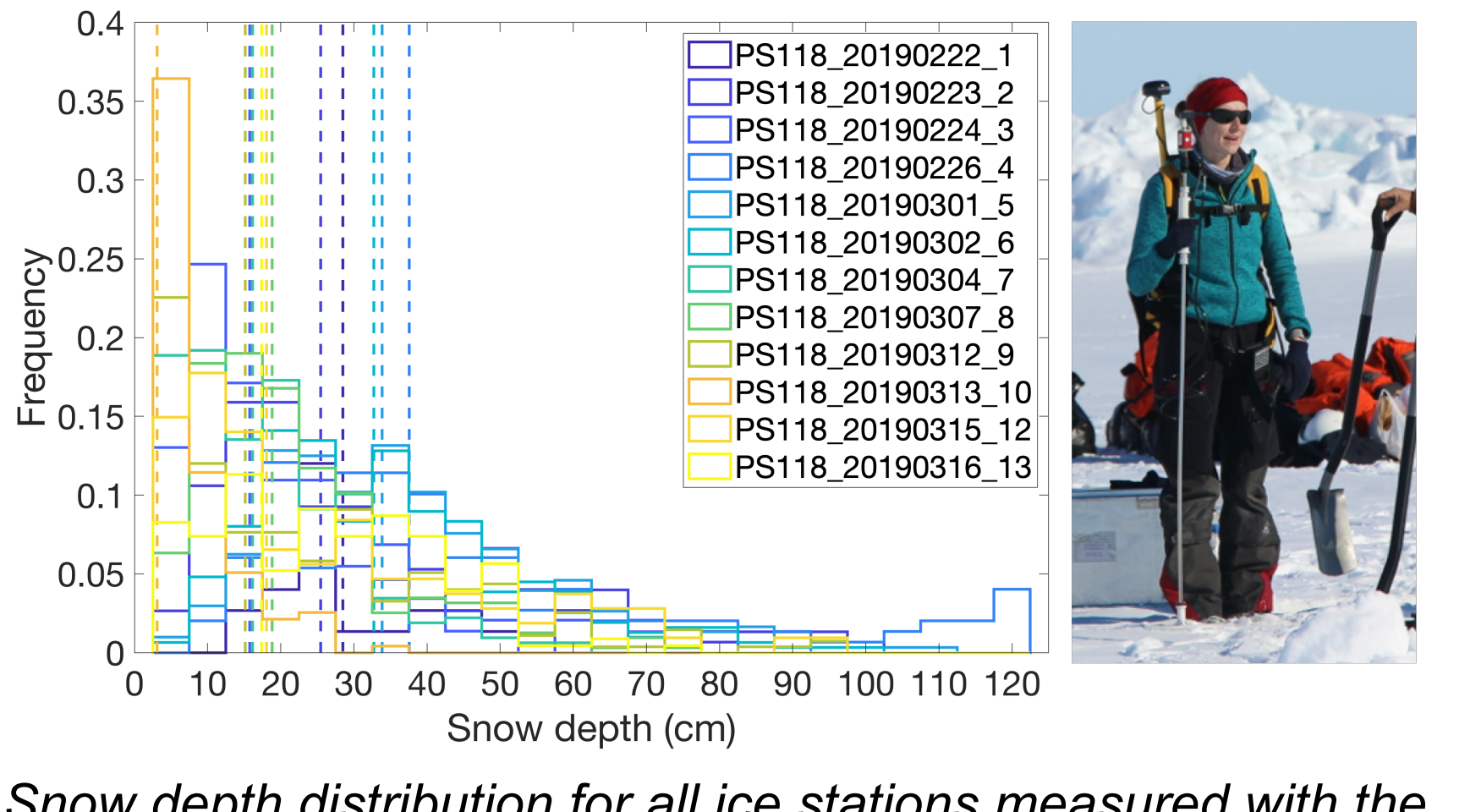

Snow depth disti
MagnaProbe.

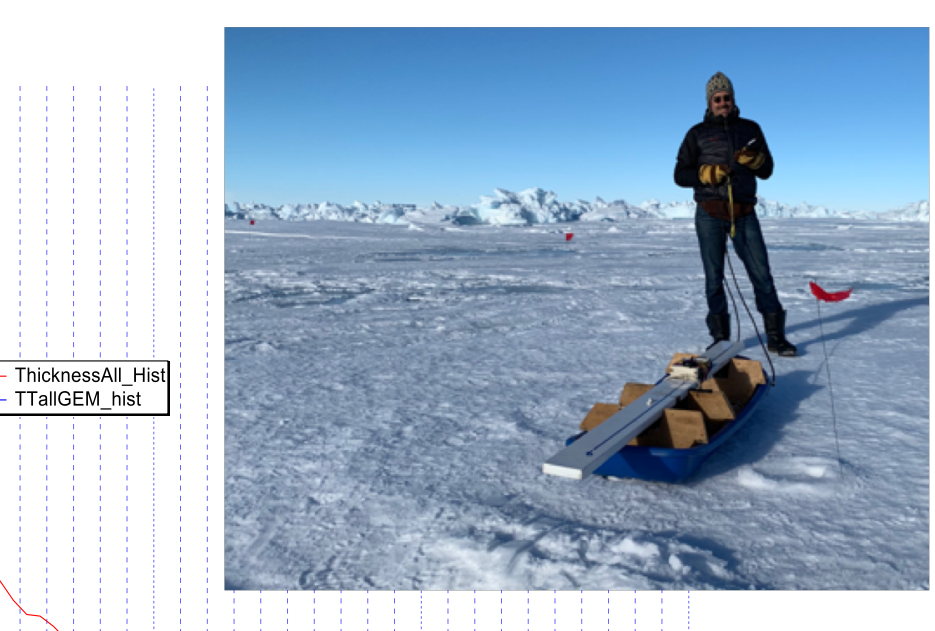

